\title{
LEADER PROPERTIES AND ATTACHMENT PROCESS IN POSITIVE TRIGGERED LIGHTNING FLASHES
}

\author{
M. Chen, N. Takagi, T. Watanabe, D. Wang (Gifu University) \\ Z-I. Kawasaki, T. Ushio (Osaka University) \\ M. Nakano (Toyota National College of Technology) \\ K. Nakamura (Nagoya Inst. of Technology) \\ S. Sumi (Chubu University) \\ C. Wang, X. Liu, X. Qie (Lanzhou Inst. of Plateau Atmospheric Physics, China) \\ C. Guo (Shanghai Meteorological Bureau, China)
}

\begin{abstract}
Properties of leader development and attachment process in two positive triggered lightning flashes, 9703 and 9704, initiated by "altitude" and "classical" technique respectively, in northwest plateau area of China in 1997, were investigated. Coordinated observations of electric field changes, current and high-speed video pictures were used to derive the main chronological sequence of events. For flash 9703 , when the ascending rocket reached $500 \mathrm{~m}$ above the ground, a negative upward leader was firstly initiated from the upper end of the triggering wire. This led depositing of positive charge at the lower end of the triggering wire, and induced a positive downward leader there a few microseconds later. About $214 \mu \mathrm{s}$ later, a negative connecting leader from the upper end of the grounded wire was initiated. The downward positive leader and the upward negative connecting leader appeared to be connected about $10 \mu \mathrm{s}$ before the following mini-return stroke, a main breakdown process in the initial stage of altitude rocket triggered lightning. All these three leaders propagated step-wisely with a common step interval of $55 \sim 127 \mu \mathrm{s}$. Flash 9704 was a slow discharge initiated by an upward negative stepped leader from the upper end of the triggering wire.
\end{abstract}

Key words: altitude-triggering lightning, bi-directional leader

\section{Introduction}

Investigation of the leader development and its attachment to an object involved in a cloud-to-ground lightning flash (CG) is essential for design of protection of structures against lightning. In most of the cases, a CG is initiated by either a downward negative stepped leader starting from the cloud or an upward positive leader starting from the top of tall ground structures ( $-\mathrm{CG})$. However, in winter thunderstorms in Hokuriku area of Japan [Takeuti et al., 1976], in summer thunderstorms in north plateau area of China [Liu et al., 1989, 1994] and in Switzerland [Berger et al., 1965], it has been found there is a high proportion of CGs initiated by downward positive leaders from the cloud or upward negative leaders from tall ground structure (+CG).

The physical mechanism of leader development, especially the attachment process occurring close to ground, can only be well studied by measurements made in very close distance. The artificially triggering lightning technique allows doing such close observations, and therefore has been used in their studies of leaders by many researchers (e.g., Laroche et al. [1991] and Lalande et al. [1998] on negative triggered lightning; Kawasaki et al. [1992] and Liu et al. [1994] on positive triggered lightning). Adding to the above works, here we report the results of a triggering lightning experiment carried out in the summer of 1997 at Pingliang, Gansu, in northwest plateau area of China. Summer storms in this area usually have a triple electrical structure with a thick and broad pocket positive charge region near cloud bottom [Liu et al., 1989]. It is because of this special triple electric structure of the 
thunderclouds that so far only positive discharges have been triggered successfully in this area. The purpose of this experiment has been to investigate the development of different types of leaders and the ground attachment process under positive ambient electric field (positive charge overhead).

\section{Triggering Lightning Technique and Instrumentation}

Two methods, termed "classical triggering lightning technique" and "altitude-triggering lightning technique", respectively, were employed in the experiment. The "classical triggering technique" involves an upward launching of a small rocket trailing a steel wire tied to a $4 \mathrm{~m}$ high lightning rod grounded via current measuring system. When the rocket ascended to typically 300 to $500 \mathrm{~m}$ high at a speed of about $150 \mathrm{~m} / \mathrm{s}$, the electric field enhancement near the upper end of the steel wire is high enough to trigger a negatively charged leader extending toward the cloud, followed by a continuous current process along the wire trace. Usually no leader/return stroke sequence follows the continuous current process.

The "altitude triggering technique" used in this experiment is similar to that introduced by Lalande et al. [1998] (see Figure 1). The rocket first spools out $50 \mathrm{~m}$ of grounded "intercepting" steel wire followed by $86 \mathrm{~m}$ long nylon cable, and then a second "triggering" steel wire is unreeled. The "intercepting" wire, as in the classical case, is grounded via the $4 \mathrm{~m}$ high lightning rod. The lightning triggered by using this technique involves a bidirectional leader system from extremities of the triggering wire (the leaders $A$ and $B$ in Figure 1) and an upward negative connecting leader from the tip of the intercepting wire (the leader $\mathrm{C}$ in Figure 1). Following the connection between the upward negative connecting leader $\mathrm{C}$ and the downward positive leader $\mathrm{B}$ is a so-called "mini-return stroke" process.

The observation sites related to this study were sites 1,2 and 3 , which located at $70 \mathrm{~m}$, $750 \mathrm{~m}$ and $6.6 \mathrm{~km}$, respectively, from the triggering site. The current at the bottom of a lightning channel (base current) was detected by using a $5.47 \mathrm{~m} \Omega$ coaxial current shunt resistance. The signal from the shunt was sent

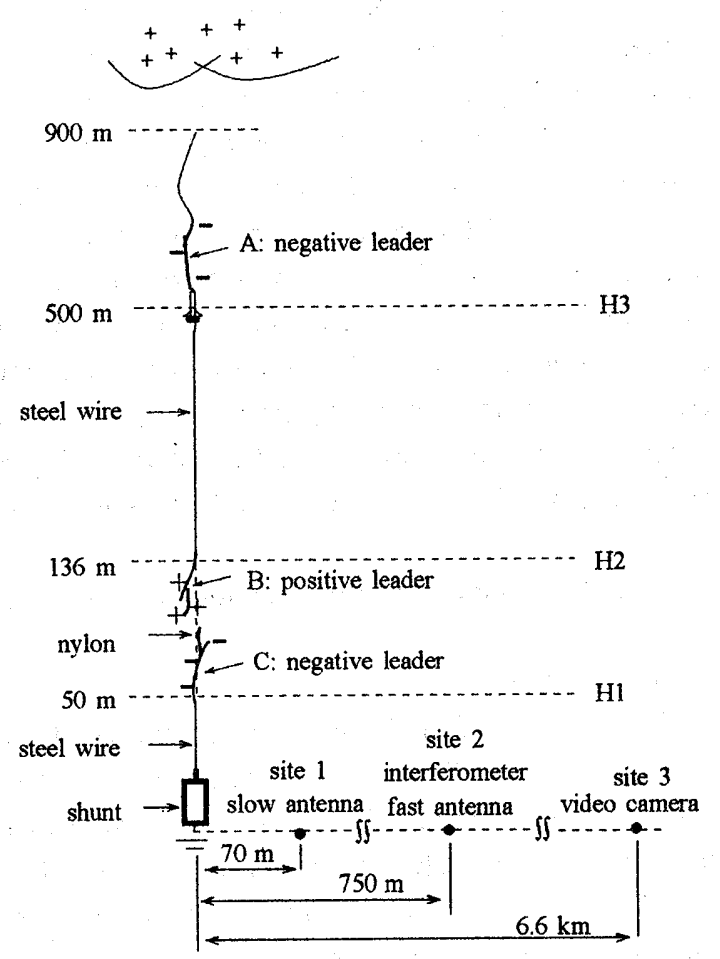

Figure 1. Illustration of the leader phase in the altitude-triggered lightning 9703 . via a fiber-optic system to a DL708 digitizing recording system operating at a $10 \mathrm{MHz}$ sampling rate with 10 bit amplitude resolution located at site $\mathrm{A}$. The frequency bandwidth of the current measuring system was from $10 \mathrm{~Hz}$ (set by the fiber-optic system) to $5 \mathrm{MHz}$ (set by the DL708). Electric fields were measured using a flat-plate slow antenna system (bandwidth $5 \mathrm{~Hz} \sim 5 \mathrm{MHz}$, sampling rate $3.125 \mathrm{MHz}$, value resolution 12 bit ) at both sites 1 and 2 and a flat-plate fast antenna system (bandwidth $160 \mathrm{~Hz} \sim 0.5 \mathrm{MHz}$, sampling rate $1 \mathrm{MHz}$, value resolution 12-bit) at site 2 . The output of the slow antenna at site 1 was also recorded on the DL708 for time coordinating with the current record. A broad band interferometry system [Ushio et al., 1997] was placed at site 2 with its time being synchronized with the fast antenna system via a GPS (Global 
Positioning System). At site 3, a high speed digitizing video camera system (sampling rate 1000 frames/second, picture resolution $256 \times 256$ pixel ) was set to view the development of the lightning channel.

\section{Observation Results and Analysis}

During the experiment, we triggered successfully two lightning flashes, 9703 and 9704 at local times of 16:02:48 and 16:09:40, respectively, on July 26, 1997. Flash 9703 was triggered by using the altitude-triggering lightning technique when ground electric field being around $+5 \mathrm{kV} / \mathrm{m}$. Flash 9704 was a classical one triggered when the ground electric field being around $+7 \mathrm{kV} / \mathrm{m}$. Both were positive discharges transferring positive charges from cloud to ground. Earlier awareness of the clearly visible images of the upward negative stepped leader process in flash 9704 helps us in identification of the same type events involved in the flash 9703 . Therefore we present the analysis of the 9704 first.

\subsection{Classical Triggered Lightning: 9704}

The high speed digitizing camera video record at site 3 (Figure 2) and the slow antenna record at site 2 (Figure 3) were available for analysis of the flash 9704. As evident in frame 04 of Figure 2, when the rocket ascended to about $250 \mathrm{~m}$ high, a leader is initiated from the tip of the wire and has extended

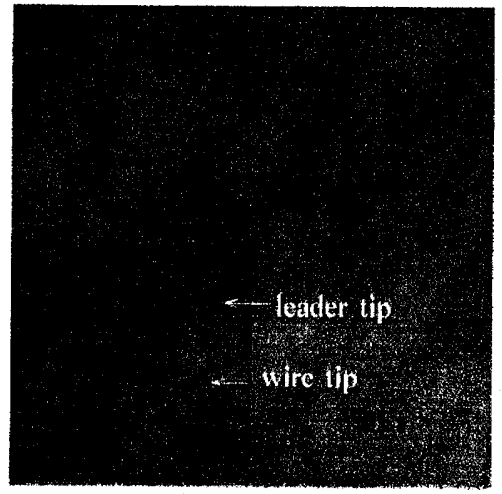

frame 04

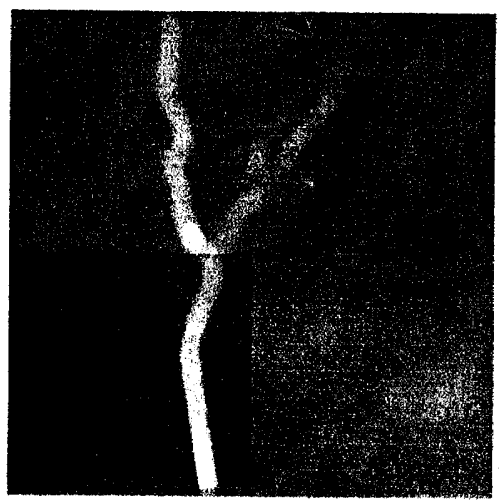

frame 06

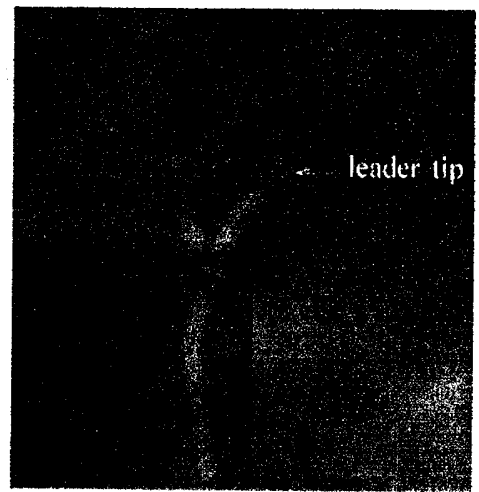

frame 05

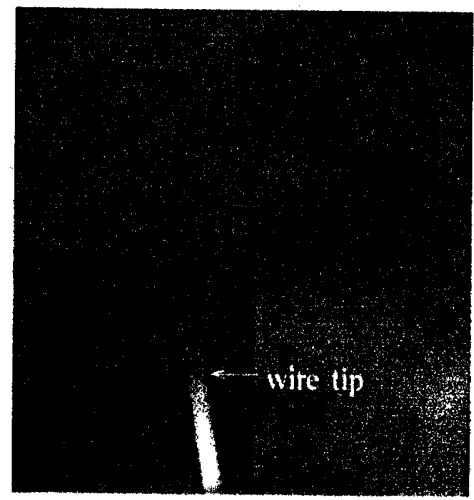

frame 24

Figure 2. High speed video pictures of flash 9704 taken at $6.6 \mathrm{~km}$ away. The time interval between frames is $1 \mathrm{~ms}$. The height viewed by one frame is about $1000 \mathrm{~m}$. 

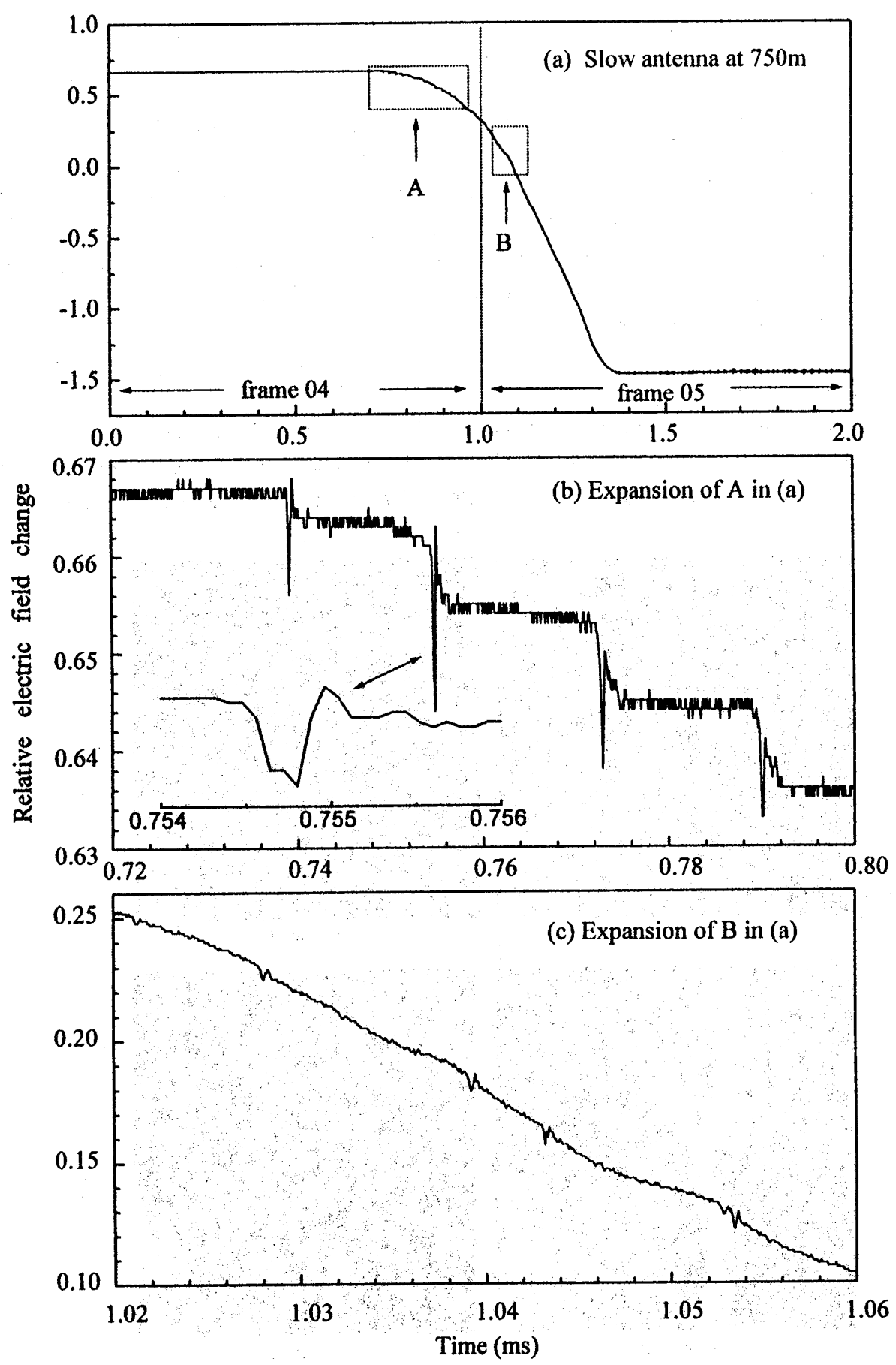

Figure 3. Electric field change performed on flash 9704 measured by slow antenna at $750 \mathrm{~m}$ (site 2) from the lightning channel . 
about $150 \mathrm{~m}$ toward the cloud. The leader at this stage has been identified as a stepped negative leader as it produces a series of negative stepwise electric field changes at site 2 (Figure $3 b$ ). The step time interval ranges from 16 to $20 \mu \mathrm{s}$. In frame 05 of the figure, the leader develops into two branches at a height around $500 \mathrm{~m}$ with their tips being around $750 \mathrm{~m}$ high. The leader has extended about $350 \mathrm{~m}$ within $1 \mathrm{~ms}$ (from frames 04 to 05 ), indicating that its propagating velocity is at least $3.5 \times 10^{5} \mathrm{~m} / \mathrm{s}$. Weak light along the wire trace in frame 05 probably suggests that the wire has been melted and vaporized at this moment. The electric field change at this time is characterized with several pulse and ramp changes superimposing on a decreasing slope (Figure 3c). The slope change is obviously due to a continuous current inside the leader channel, and the pulses and ramps probably due to some stepwise leader breakdown processes near the tips of leader branches. In frame 06 , the channel further branches into 4 as they extending toward the cloud, with one of them being much brighter than the others. Following this is a continuous current process, which lasting more than $30 \mathrm{~ms}$ determined from the video pictures.

\subsection{Altitude-Triggered Lightning: 9703}

High speed camera pictures (Figure 4) have been used to derive the main events involved in flash 9703. As shown in frame 02 of Figure 4, when the rocket is around $500 \mathrm{~m}$ high, three leaders appear at the extremities of the wires: an upward negative leader from the upper end of the triggering wire (leader A), a downward positive leader from the lower end of the triggering wire (leader B) and a negative

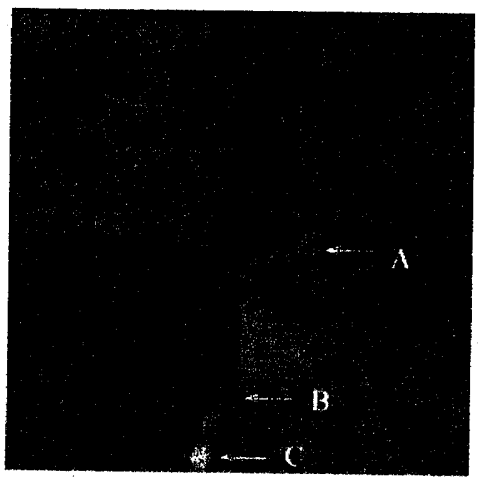

frame 02

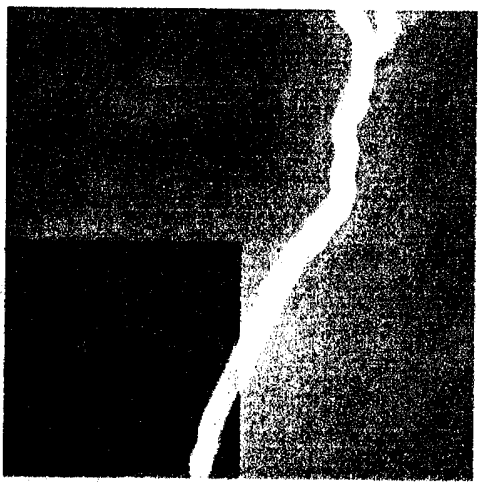

frame 04

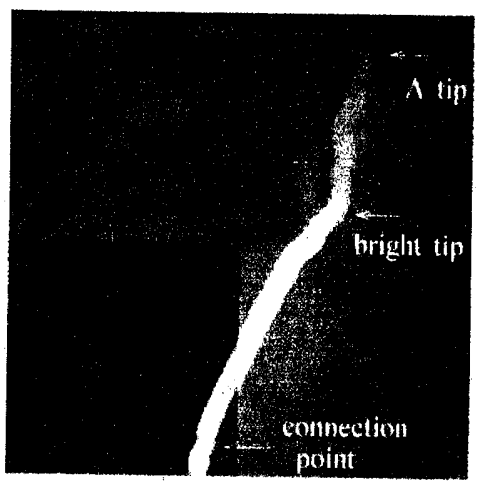

frame 03

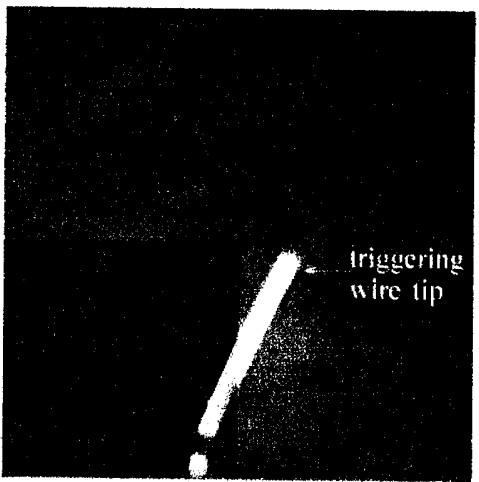

frame 20

Figure 4. High speed video pictures of flash 9703 taken at $6.6 \mathrm{~km}$ away. The time interval between frames is $1 \mathrm{~ms}$. The height viewed by one frame is about $1000 \mathrm{~m}$. 
connecting leader from the tip of the intercepting wire (leader $C$ ). Within the following $1 \mathrm{~ms}$ (frame 03 of Figure 4), (1) leader A extends forward about $300 \mathrm{~m}$ (from $600 \mathrm{~m}$ to $900 \mathrm{~m}$ high), (2) the connection between leaders $B$ and $C$ is established with the connecting point being around $80 \mathrm{~m}$ high above ground, and (3) the so-called "mini-return stroke" occurs, followed by an upward bright discharge process along the traces of the wire and the leaders with the tip (labeled 'bright tip' in frame 03 of Figure 4) of the bright discharge being $600 \mathrm{~m}$ high above the ground. Therefore, the speed of leader $A$ should be around $3 \times 10^{5} \mathrm{~m} / \mathrm{s}$, and that of the bright discharge process be greater than $6 \times 10^{5} \mathrm{~m} / \mathrm{s}$. In frame 04 , the bright discharge front has caught up with leader $\mathrm{A}$ and further rushes to the cloud. Following this is a continuous current process as that in the classical case.

The details of the chronological sequence of the events including the leader onset, the connecting process and the "mini-return stroke" (see Figure 5) have been derived in basis of measurements of the electric fields, the base current and the broad band interferometry system (see Figure 6). The time in Figure 6 is coordinated by setting the occurring time of the mini-return stroke identified from each measurement at sites 1 and 2 to time 0 . As shown by the simulation in Section 4 (see Figure 10), the slow antenna at site $1(70 \mathrm{~m}$ from the triggering site) is sensitive to leaders $B$ and $C$ at the lower part of channel, while the fast antenna at site $2(750 \mathrm{~m}$ from the triggering site) is more sensitive to the

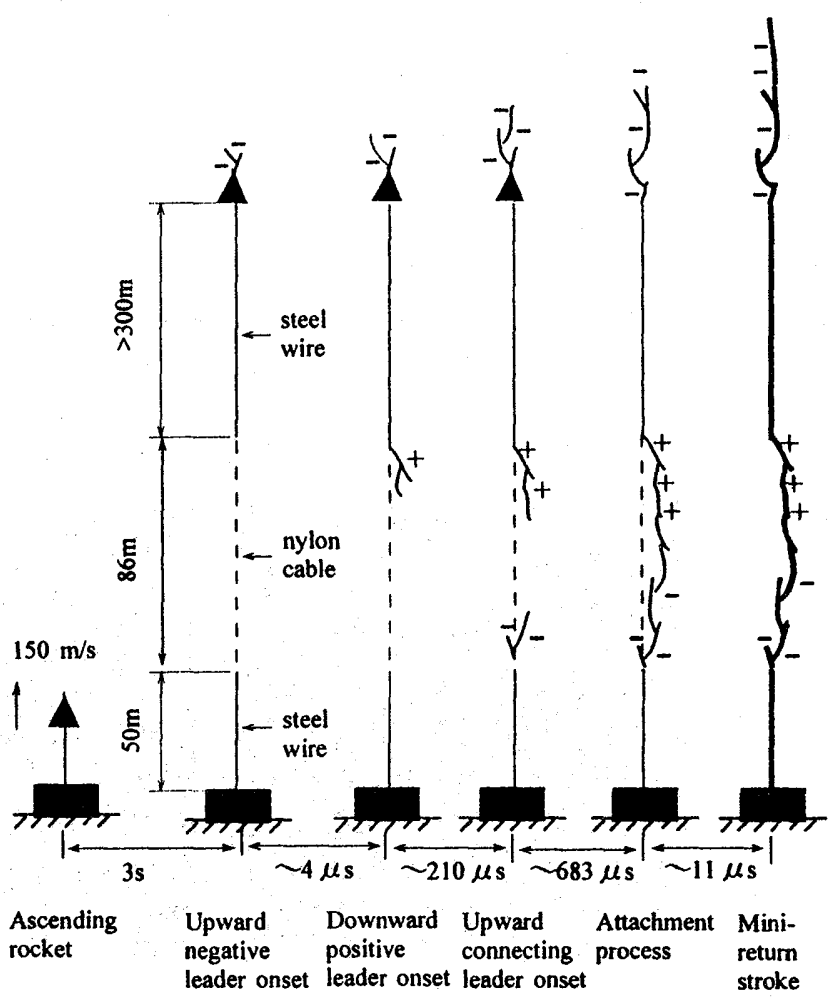

Figure 5. Chronological sequence of events involved in flash 9703 as inferred from the electric field measurements for the bidirectional leader and from the current for the connecting leader. leader $A$ at the top of the triggering wire. In the paragraphs to follow, the properties of leader A are derived mainly based on the electric field measurement at site 2 , and those of leaders $\mathrm{B}$ and $\mathrm{C}$ are mainly based on the measurements at site 1 .

From time $\mathrm{tl}(\mathrm{tl}=-908 \mu \mathrm{s}$ in Figures 6 and 7), the electric field at site 1 begins to increase in step with each step change accompanied by a bipolar pulse (Figures $6 \mathrm{~b}$ and $7 \mathrm{~b}$ ), indicating a positive leader begins to extend downward stepwise from the lower end of the triggering wire (the leader $B$ ). Simultaneously, the electric field at site 2 begins to decrease with pulse/step changes superimposing on a decreasing slope (Figures $6 \mathrm{c}$ and $7 \mathrm{c}$ ), indicating the inception of an upward stepped negative leader from the top of the triggering wire (the leader A). The results of observation of the broad band interferometry system also show that these pulse/steps at site 2 are originated near the top of the triggering wire. 


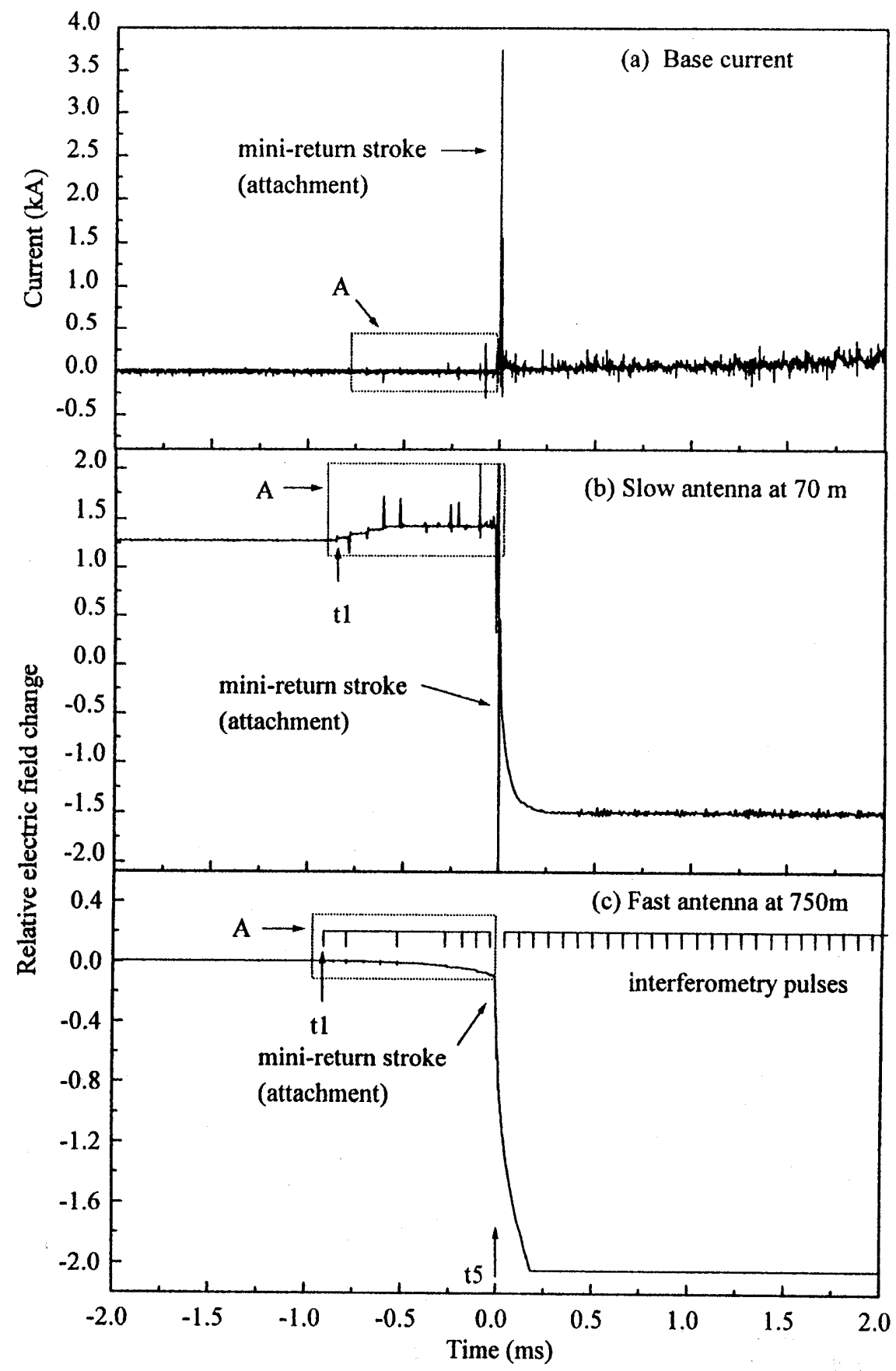

Figure 6. Measurements of (a) the base current, (b) the electric field change by the slow antenna at site $1(70 \mathrm{~m}$ from the flash), and (c) the electric field change by the fast antenna and the pulses by the broad band interferometry system at site $2(750 \mathrm{~m}$ from the flash), for flash 9703. 


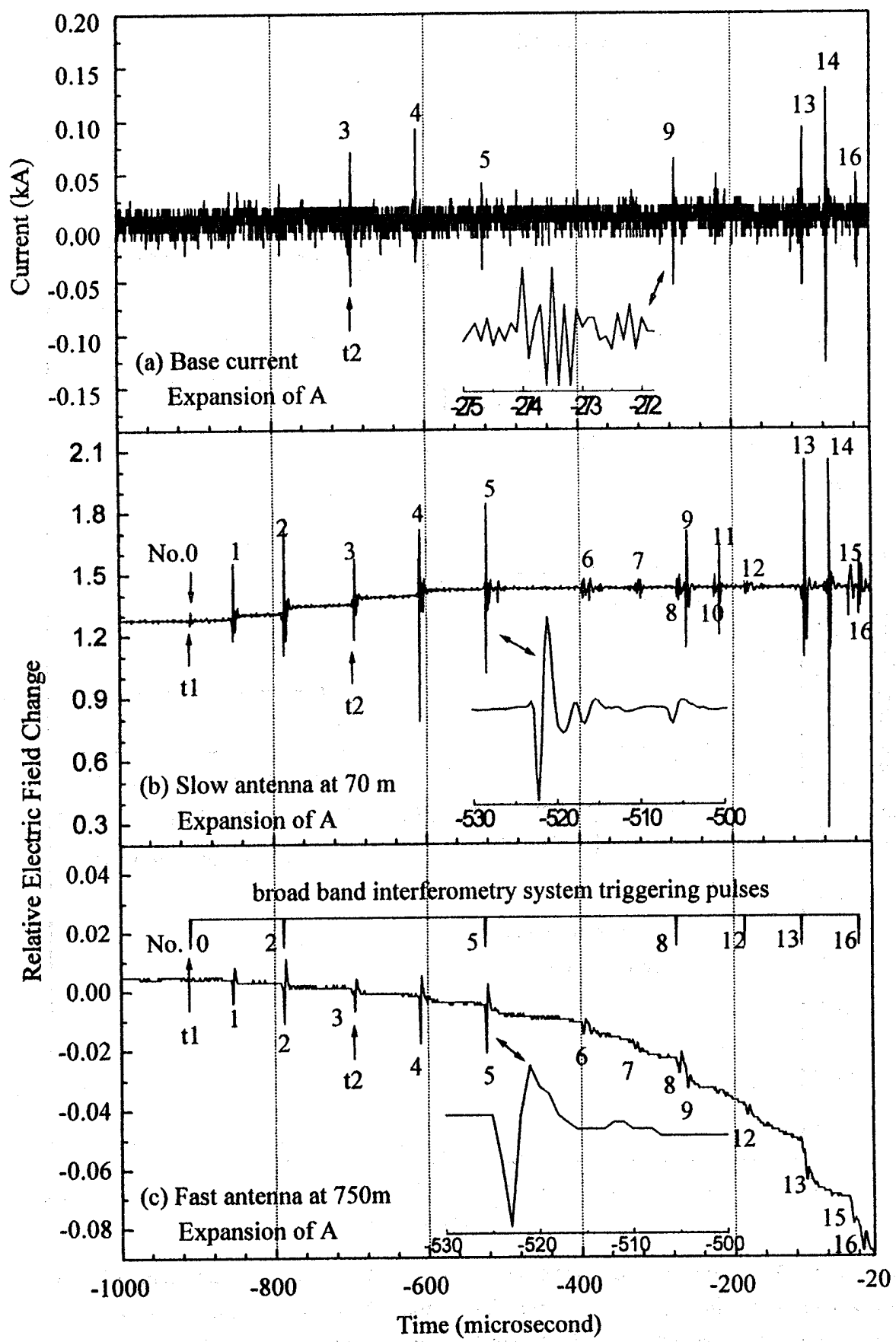

Figure 7. Same as the Figure 6 but the expansion of the leader developing part A. 
Leaders A and B appear as a typical bidirectional leader system with a common mean stepping period of $90 \mu \mathrm{s}$ (ranges from 55 to $127 \mu \mathrm{s}$ ). To study the coupling between the two leaders, the difference between the arrival times of the corresponding pulse/step at sites 1 and 2 has been investigated (Figure 8). The results show that the arrival time of a pulse/step at site 2 is prior to that of the corresponding pulse/step at site 1 by $0.72 \sim 4 \mu \mathrm{s}$, with the prior time increases when the leaders extend forward. Also the pulses at the site 2 are wider than that at the site 1. According to the simulation in Section 4 (see Figure 11), these suggest an unique probable coupling process as following: each time when the negative leader A extends upward one step (represented by the pulses at site 2), a positive current surge (positive charge going down) is generated at the tip of leader A simultaneously. This positive current surge propagates along the triggering wire down to the tip of the positive leader $B$, resulting in immediately that the leader B extends forward one step too (represented by the pulses at site 1).

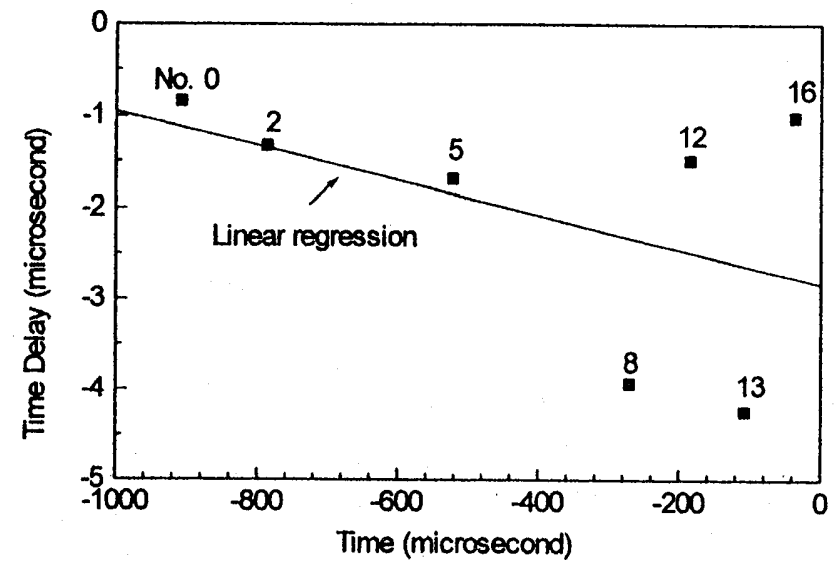

Figure 8. Time delay between the broad band pulses in Figure 7c and the pulses in Figure $7 \mathrm{~b}$. Minus delay time means that the arrival time of the pulses at site 2 ( $750 \mathrm{~m}$ from the flash) is prior to that of the pulses at site 1 (70 $\mathrm{m}$ from the flash). The occurring time of the mini-return stroke is set to time 0 at both sites.

At time $\mathrm{t} 2(\mathrm{t} 2=-694 \mu \mathrm{s}$ in Figure 7), the first current pulse (labeled 3 in Figure 7a) is detected, indicating the inception of a negative connecting leader from the tip of the grounded wire (the leader $\mathrm{C}$ ). From $t 2$ to $t 3(t 3=-16 \mu \mathrm{s}$, the pulse a in Figure 9), the connecting leader current shapes oscillating pulses separated in similar time intervals to that of the bidirectional leader (55 to $127 \mu \mathrm{s}$ ). The amplitudes of the current pulses during this period are around $\pm 100 \mathrm{~A}$. As the continuous current is almost zero, we speculate that the connecting leader $\mathrm{C}$ in this stage extends upward very slowly. The increasing slope of the electric field at site 1 becomes gentle from $t 2$ and finally becomes into a flat plateau (Figures $6 \mathrm{~b}$ and $7 \mathrm{~b}$ ). As shown by the simulation in Section 4 (Figure 10a), this is probably because that the negative charges deposited in the leader $\mathrm{C}$ contributes a minus electric field change at site 1 , which eliminating part of the positive field changes produced by the leader $\mathrm{B}$.

The contact between the leaders $B$ and $C$ is believed to be established during time $t 3$ to $t 5$ ( $t 5=0 \mu \mathrm{s}$, the pulse $c$ in Figure 9), as the amplitudes of both the impulsive current and the continuous current have a rapid increase during this period. There are three current pulses (the pulses $a, b$ and $c$ in Figure 9a) separated by $5 \mu \mathrm{s}$ and $11 \mu \mathrm{s}$ respectively, in this period. The amplitude of the pulse a is about $+900 \mathrm{~A}$, and that of the pulse $\mathrm{b}$ is around $+1200 \mathrm{~A}$. Both are much greater than those before $\mathrm{t} 3$. The continuous current begins to increase quickly from $\mathrm{t} 4(\mathrm{t} 4=-16 \mu \mathrm{s})$ and has reached about $+400 \mathrm{~A}$ within $10 \mu \mathrm{s}$. 


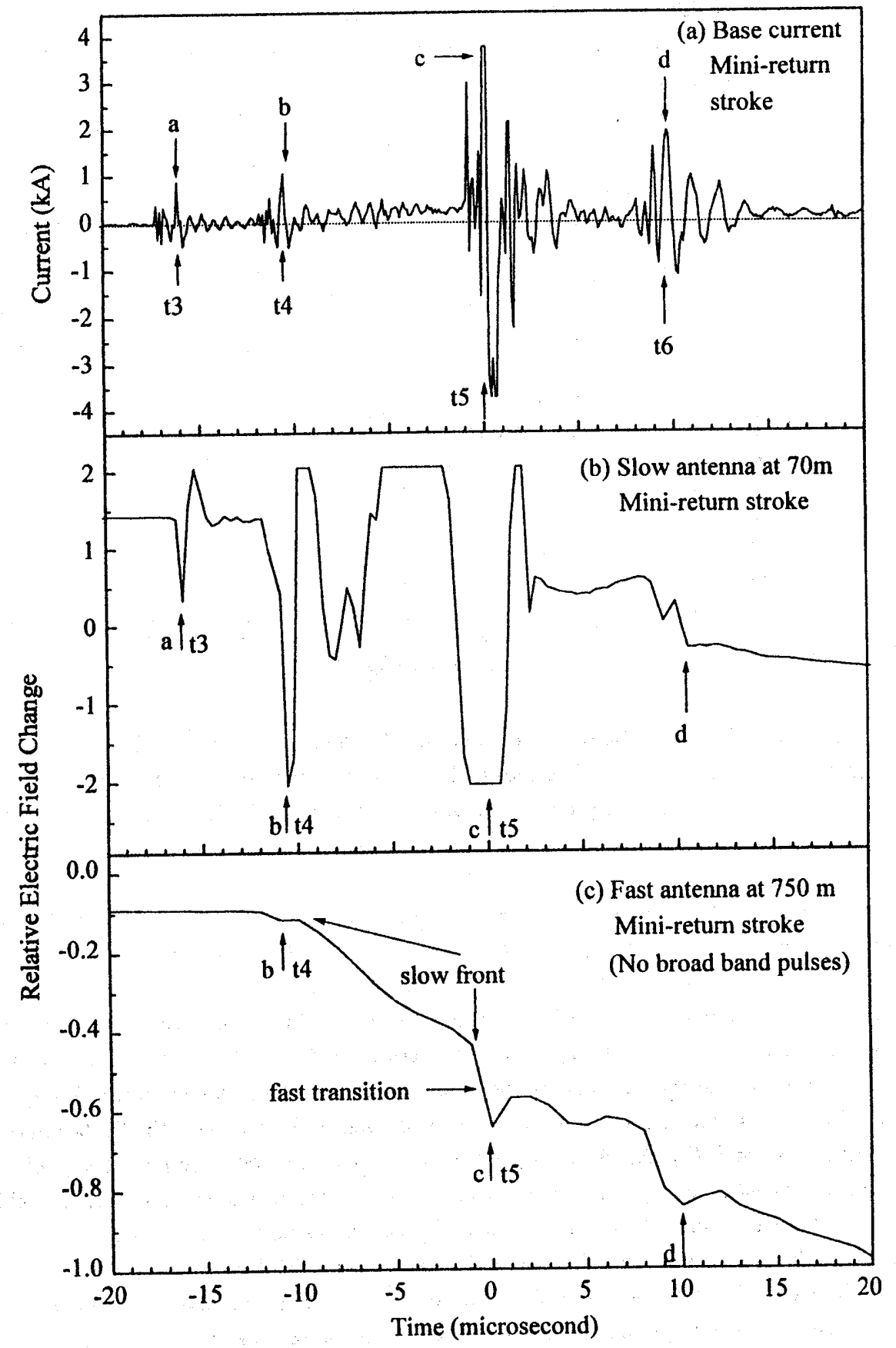

Figure 9. Same as the Figure 6 but the expansion of the "mini-return stroke" part. 
Corresponding to the three current pulses, there are also three big pulses in the electric field observation at site 1 ( the pulses a, b and $\mathrm{c}$ in Figure 9b). At site 2, the electric field change in this period shows a waveform similar to that of a natural positive return strike, including a "slow front" and a "fast transition" (Figure 9c). From the video picture, the estimated connection point is about $30 \mathrm{~m}$ above the tip of the grounded wire. Combining this with the starting and ending times of the leaders $\mathrm{B}$ and $\mathrm{C}$, the average speeds are estimated to be about 6.0 and $4.0 \times 10^{4} \mathrm{~m} / \mathrm{s}$, for the leaders $B$ and $C$, respectively.

At time $\mathbf{t 5}$, the so-called "mini-return stroke" occurs with a peak current of more than $4 \mathrm{kA}$. We call this process the name of "mini-return stroke" just for discrimination from the natural return stroke. It is worth noting that there is another current pulse (the pulse $d$ in Figure 9a) appearing at time t6, $10 \mu \mathrm{s}$ later after the "mini-return stroke". This pulse is probably related to the bright discharge process identified from the video picture (frame 03 in Figure 4).

\section{Simulation on Leader Developing Phase of Flash 9703}

The calculation of the electric field intensity $E$ at distance $d$ due to a vertical charged line of length $y-x(y>x)$ with charge per unit length $\rho$ located above a conducting plane is given by

$$
E=\left(\begin{array}{llll}
\rho / 2 & \pi & 0
\end{array}\right)\left[1 /\left(d^{2}+x^{2}\right)^{1 / 2}-1 /\left(d^{2}+y^{2}\right)^{1 / 2}\right] .
$$

where $\varepsilon_{0}=8.85 \times 10^{-12} \mathrm{~F} / \mathrm{m}$, is the dielectric constant of air [see Uman, 1969].

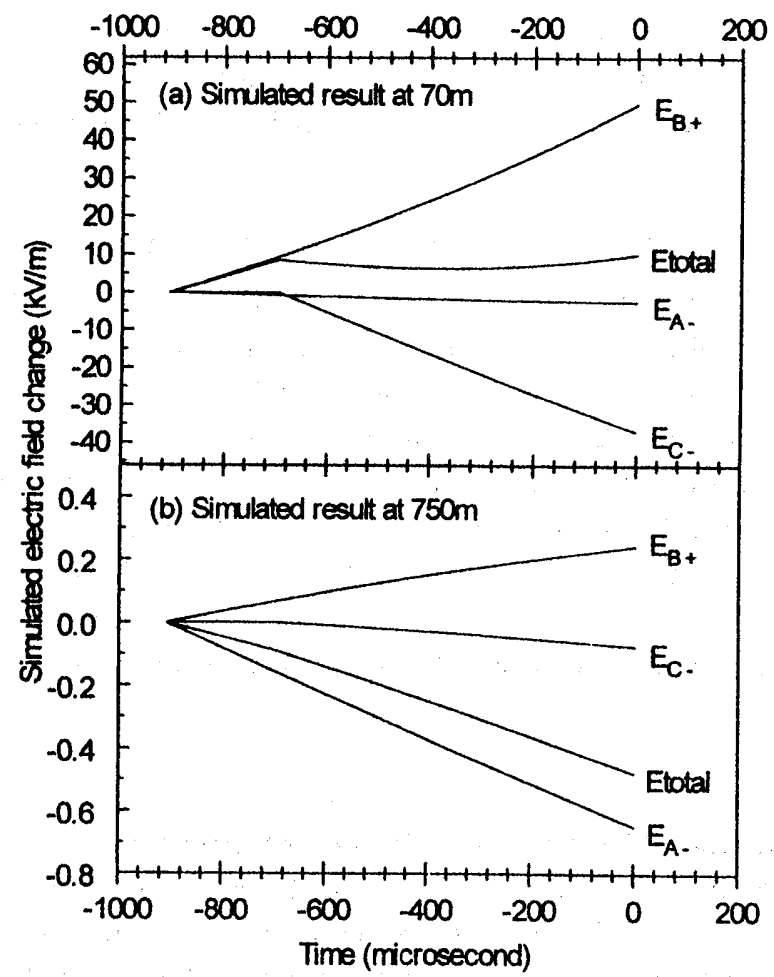

Figure 10. Simulated electric field changes at site 1 (70 $\mathrm{m}$ from the flash) (a) and site

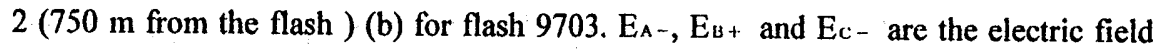
changesdue to leaders $\mathrm{A}, \mathrm{B}$ and $\mathrm{C}$, respectively, and Etotal is the total electric field change due tothe three leaders. The leader speeds are $3.0,0.6$ and $0.4 \times 10^{5} \mathrm{~m} / \mathrm{s}$ and the linear chargedensities are $-0.2,+1.0$ and $-1.0 \mathrm{mC} / \mathrm{m}$, for leaders $\mathrm{A}, \mathrm{B}$ and $\mathrm{C}$ respectively. 
Suppose that there are three leaders $\mathrm{A}, \mathrm{B}$ and $\mathrm{C}$ initiated from $\mathrm{H} 3=500 \mathrm{~m}, \mathrm{H} 2=136 \mathrm{~m}$ and $\mathrm{H} 1=$ $50 \mathrm{~m}$ ), respectively (see Figure 1). The leader A starts at time $\mathrm{tl}(\mathrm{tl}=-908 \mu \mathrm{s})$ and extends upward at speed $V_{A}\left(3.0 \times 10^{5} \mathrm{~m} / \mathrm{s}\right)$ with a linear charge density of $\rho_{A}(-0.2 \mathrm{mC} / \mathrm{m})$. The leader $B$ starts at time $t 1$ and extends downward with a speed of $V_{B}\left(6.0 \times 10^{4} \mathrm{~m} / \mathrm{s}\right)$ and a linear charge density of $\rho_{\mathrm{B}}(+1.0$ $\mathrm{mC} / \mathrm{m}$ ). The total charge of the leaders $A$ and $B$ keeps zero when extending forward ( $V_{A} \rho_{A}+V_{B} t \rho_{B}$ $=0)$. The leader $\mathrm{C}$ is supposed to start at $\mathrm{t} 2(\mathrm{t}=-694 \mu \mathrm{s})$ and extends upward at speed $\mathrm{V}_{\mathrm{c}}\left(4.0 \times 10^{4}\right.$ $\mathrm{m} / \mathrm{s})$ with a linear charge density of $\rho_{\mathrm{c}}\left(-1.0 \mathrm{mC} / \mathrm{m}\right.$, the same value as $\rho_{\text {в }}$ without the polarity). In such an assumption, the mean leader current ranges between 40 to $60 \mathrm{~A}$, which is close to the 50 and 63 amperes measured with a magnetometer by Williams and Brook [1963]. The vertical electric field intensities at sites $1(\mathrm{~d}=70 \mathrm{~m})$ and $\mathrm{B}(\mathrm{d}=750 \mathrm{~m})$ due to the three leaders have been calculated. The results are shown in Figure 10. From the results: (1) The electric field at site 1 is mainly subjected to the leaders $\mathrm{B}$ and $\mathrm{C}$, showing an positive increasing which being rapid at the beginning and then slowdown. The slope-plateau shape is due to the appearance of the connecting leader C. (2) The electric field at site 2 is predominated by the upper negative leader $A$, showing a decreasing toward negative.

For a current $i(t)$ within a short vertical channel of length $d z$ centered at height of $z$, the vertical radiation electric field for a point $\mathbf{P}$ on ground with a horizontal distance $d$ from the channel is

$$
\mathrm{dE}(\mathrm{d}, \mathrm{t})=-\left(1 / 2 \mathrm{c}^{2} \pi \quad \varepsilon \quad 0\right) \cdot\left(\mathrm{d}^{2} / \mathrm{r}^{3}\right) \cdot[\partial \mathrm{i}(\mathrm{z}, \mathrm{t}-\mathrm{r} / \mathrm{c}) / \partial \mathrm{t}] \cdot \mathrm{dz}
$$

Where $c=3.0 \times 10^{8} \mathrm{~m} / \mathrm{s}$ is the light speed, and $\mathrm{r}=\left(\mathrm{d}^{2}+\mathrm{z}^{2}\right)^{1 / 2}$. In the case that a positive current pulse $\mathrm{i}(\mathrm{t})$ (positive charge down) is produced by the leader $\mathrm{A}$ at $\mathrm{H3}=500 \mathrm{~m}$ and then propagates along the triggering wire to the leader $\mathrm{B}$ at $\mathrm{H} 2=150 \mathrm{~m}$ with a speed of $\mathrm{v}=2.5 \times 10^{8} \mathrm{~m} / \mathrm{s}$, the vertical radiation electric field at point $P$ is

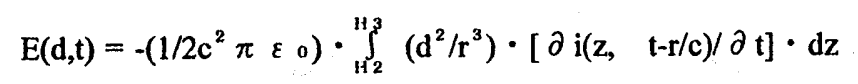

where $\quad i(z, t)=i(H 3, t-H 3 / v+z / v)$

For $\mathrm{d}=70 \mathrm{~m}$ (site 1) and $750 \mathrm{~m}$ (site 2), the simulated results with a spatial integral step of $50 \mathrm{~m}$ and atemporal differential step of $0.1 \mu \mathrm{s}$ are illustrated in Figure 11. From the figure, the total electric field Etotal at the site 1 is mainly from the lower part of the channel with its negative peak time being close to that of the partial field from the leader B, while that at the site 2 comes evenly from the whole channel with its negative peak time being close to that of the partial field from the leader A. Meanwhile, the pulse width of Etotal at the site 2 is much wider than that at the site 1 . The negative peak time of Etotal at site 2 is prior to that at site 1 by more than $1 \mu \mathrm{s}$, which is obviously due to the assumption of downward propagation of the current pulse. This prior time increases as the two leaders extending forward.

\section{Discussions}

\subsection{Properties of the Bidirectional Leader in Altitude-triggered Lightning}

For flash 9703, our analysis suggests that the onset of the upper negative part is prior to that of the lower positive part by a few of microseconds. However, for the bidirectional leader triggered under negative ambient electric field [Lalande et al., 1998], it has been found that the inception of the upper positive part is prior to that of the lower negative part by more than $3 \mathrm{~ms}$. The difference between these two results may be related to two factors: the shielding effect of space charge and the inception threshold of a leader. In general, there is a space charge sheath around the extremities of a still conductive wire floating in electric fields. This space charge sheath makes the initiation of a leader from the extremities be difficult by. weakening the local field. When the conductor moves at a speed greater 
than the ions drift velocity, the local field can keep free from the shielding effect by leaving the space charge behind. In laboratory [Les Renardieres Group, 1972,1981], it has been proven that the inception threshold for a positive leader is lower than that for a negative one. In the case of negative altitude-triggered lightning (e.g., Lalande et al., [1998] ), after the upper positive leader is initiated, it needs time to transfer enough negative charge to the lower end of the wire to make the local field strong enough for triggering a negative leader in present of the space charge effect. In our case, the positive ambient electric field at the upper moving end of the triggering wire enhances first to the inception threshold of the negative leader. After the negative leader is initiated, the lower positive leader is immediately initiated, as it needs only a little of positive charge injection from the upper negative leader to enhance the local electric field to the inception threshold of a positive leader over the space charge shielding effect.

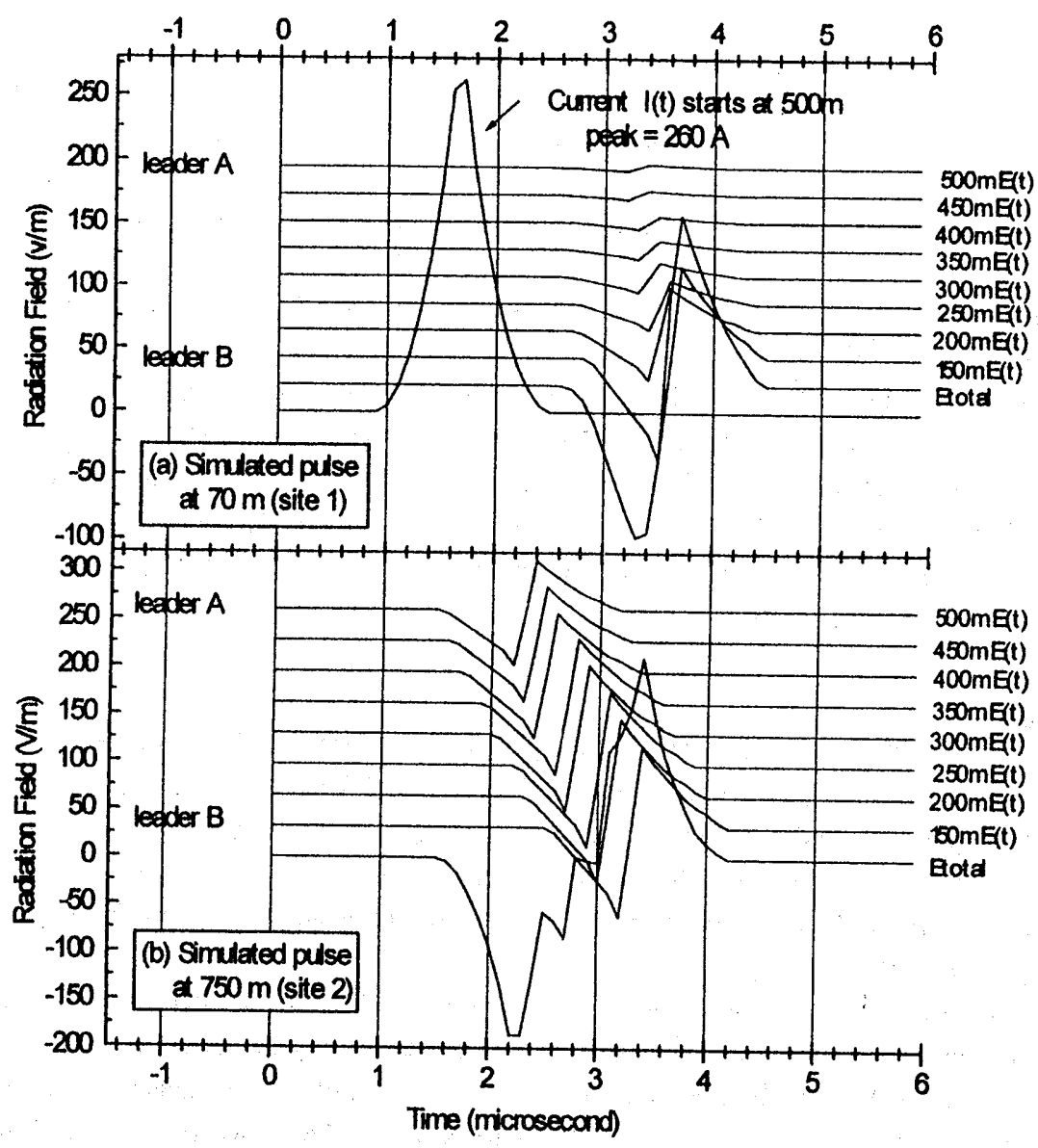

Figure 11. Simulated radiation pulses at site 1 ( $70 \mathrm{~m}$ from the flash) (a) and site 2 (750 $\mathrm{m}$ from the flash) (b) due to a current pulse starting at $500 \mathrm{~m}$ high then going down to $150 \mathrm{~m}$ at a speed of $2.5 \times 10^{5} \mathrm{~m} / \mathrm{s} .500 \mathrm{~m} \mathrm{E}(\mathrm{t})$ is the partial field due to $50 \mathrm{~m}$ long part of the channel centered at the height of $500 \mathrm{~m}$, and $450 \mathrm{~m} \mathrm{E}(\mathrm{t})$ is that at $450 \mathrm{~m}$ and so on. Etotal is the total field due to the whole channel. For consistency with Figure 8 , the time at site 2 is subtracted by $2.27 \mu \mathrm{s}$, that is, $(750-70) \mathrm{m} / 3.0 \times 10^{8} \mathrm{~m} / \mathrm{s}$. 


\subsection{Properties of the Attachment Process and the Slow Front}

The property of the attachment involved in altitude-triggered lightning can be inferred from the connecting leader current. The connecting leader current flows along a path consisted of a short metal wire and the lengthening leader channel, which may be considered as a resistance-inductance-capacitance (RLC) transmission line. Such a RLC circuit is easy to oscillate with a fast rising current pulse when the resistance is small. As the leader extending, this oscillation progressively disappears because of the growing resistance. The continuous current of the connecting leader may be associated with the charge depositing process inside the leader channel. A increasing continuous current means an fast extending leader.

Applying to Flash 9703, the oscillating shape of current pulses appearing during time t 2 to $t 3$ means that the connecting leader in this stage appears as some aborted streamer discharge or extends forward very slowly. The connecting leader begins to accelerate probably from the step at time $\mathbf{t} 3$ (pulse $a$ in Figure 9a), indicated by the increase of the continuous current and the mono-polar shape of the big current pulse. $5 \mu \mathrm{s}$ later, at time $\mathrm{t} 4(\mathrm{t} 4=-11 \mu \mathrm{s})$, a much bigger current pulse (pulse $\mathrm{b}$ in Figure 9a) appears with the peak value greater than $+1200 \mathrm{~A}$. The continuous current begins to increase quickly from this time. The electric field pulse at this time at site 1 (pulse $b$ in Figure $9 b$ ) is comparable to that (the pulse $\mathrm{c}$ in Figure $9 \mathrm{~b}$ ) produced by the following "mini-return stroke" process. Therefore, we speculate that it is this step at $t 4$ that has finished the connection between the downward positive leader $\mathrm{B}$ and the connecting leader $\mathrm{C}$. After the connection, because of the improvement of conductivity of the leader channel, the continuous current begins to increase quickly. As the continuous current increasing, it transfers more and more negative charge from ground up or drains more positive charge from the downward leader $B$ into ground, resulting in that the electrostatic fields at both sites decrease quickly.

It is worth noting that the waveform of the electric field change at site 2 , shows a similar waveform to that of a natural positive return strike, including a long "slow front" and a "fast transition" (Figure 9c ). The "slow front" begins at time $t 4$ and lasts about $10 \mu \mathrm{s}$. If the speculation about the connection of leaders $\mathrm{B}$ and $\mathrm{C}$ is correct, this means that the "slow front" is due to the quick increase of the continuous current after the connection.

\section{Summary}

Flash 9704 is a positive slow discharge starting with an upward negative stepped leader initiated from the tip of the rocket. The estimated leader speed is around $2.5 \times 10^{5} \mathrm{~m} / \mathrm{s}$, which is larger than that measured for the upward negative leaders of the winter triggered lightning flashes in Japan by using both the optical [Kito et al., 1985] and UHF radio interferometry methods [Wada et al., 1997]. The step interval ranges from 16 to $20 \mu \mathrm{s}$, consistent with many recent results observed for negative stepped leaders (e.g., Lalande et al. [1998] ).

Flash 9703 involves a bidirectional leader and an upward stepped negative connecting leader, followed by a "mini-return stroke" process. The main chronological sequence of this event is summarized in Figure 5. For the bidirectional leader, the onset of the upper negative leader is prior to that of the lower positive leader by a few of microseconds. The delay time of the onset of the connecting leader to that of the downward positive leader is about $214 \mu \mathrm{s}$. The connection between the downward leaders and the connecting leader has been inferred to occur at the time about $10 \mu \mathrm{s}$ before the following mini-return stroke. The connection point is estimated to be about $30 \mathrm{~m}$ above the grounded wire tip. Combining the electric field and the video observations, the leader speeds have been estimated. The bidirectional leader and the connecting leader have a common step interval ranging from 55 to $127 \mu \mathrm{s}$.

Our analysis suggests that the "slow front" of the electric field at side B is probably due to the 
increasing continuous current after the connection. The lasting time of the "slow front" is about $10 \mu \mathrm{s}$, which is consistent with the results observed for the first return stroke of a +CG in the same area by Takeda et al. [1998].

Acknowledgments. This research was supported in part by the grant-in-aid 0904124 for Scientific Research of Ministry of Education, Science, Sports and Culture. The authors thank the members of Gifu University, Osaka University, Toyota National College of Technology, Nagoya Institute of Technology, Chubu University, Lanzhou Institute of Plateau Atmospheric Physics, and Shanghai Meteorological Bureau for their help in the observation.

\section{References}

Berger, K., R. B. Andersen, and H. Kroninger, Parameters of lightning flashes, Electra, 80, 23-37, 1975. Kawasaki, Z-I., and V. Mazur, Common physical processes in natural and triggered lightning in winter storms in Japan, J. Geophys. Res., 97, 12935-12945, 1992.

Kito, Y., K. Horii, Y. Higashiyama, and K. Nakamura, Optical aspects of winter lightning discharges triggered by the rocket-wire technique in Hokuriku district of Japan, J. Geophys. Res., 90, 6147-6157, 1985.

Lalande, P., A. Bondiou-Clergerie, P. Laroche, A Eybert-Berard, J.-P. Berlandis, B. Bador, A. Bonamy, M. A. Uman, and V. A. Rakov, Leader properties determined with triggered lightning techniques, J. Geophys. Res., 103, 14109-14115, 1998.

Laroche, P., V. Idone, A. Eybert-Berard, and L. Barret, Observations of bidirectional leader development in triggered lightning flash, paper presented at the International Conference on Lightning and Static Electricity, NASA, Cocoa Beach, Fla, April 16-19, 1991.

Les Renardieres Group, Research on long air gap discharges, Electra 23, Moret Sur Loing, France, 1972.

Les Renardieres Group, Negative discharges in long air gaps, Electra 74, Moret Sur Loing, France, 1981.

Liu, X., Z. Ye, X. Shao, C. Wang, M. Yan, and C. Guo, Intracloud lightning discharges in the lower part of thundercloud, Acta Meteorol. Sinica, 3, 212-219, 1989.

Liu, X., C. Wang, Y. Zhang, Q. Xiao, D. Wang, Z. Zhou, and C. Guo, Experiment of artificially triggering lightning in China, J. Geophys. Res., 99, 10727-10731, 1994.

Liu, $X$., and $Y$. Zhang, Review of artificially triggered lightning study in China, T. IEE Japan, 118-B, 170-175, 1998.

Takeda, M., D. Wang, N.Takagi, T. Watanabe, M. Chen, T. Ushio, Z. Kawasaki, M. Nakano, K. Nakamura, X. Liu, X. Qie, and C. Guo, Some results of investigation on slow front of return stroke electric waveform, J. Atmos. Elect., 18, 31-39, 1998.

Takeuti, T., M. Nakano, and Y. Yamamoto, Remarkable characteristics of cloud-to-ground discharge observed in winter thunderstorms in Hokuriku area, Japan, J. Meteorol. Soc. Japan, 54, 436-439, 1976.

Uman, M. A., Lightning, pp53, Dover Publications, Inc., New York, 1969.

Ushio, T., Z-I. Kawasaki, Y. Ota, and K. Matsuura, Broad band interferometry measurement of rocket triggered lightning in Japan, Geophys. Res. Lett., 24, 2769-2772, 1997.

Wada, M., Z-I. Kawasaki, K. Matsuura, K. Nakamura, and K. Horii, UHF Radio Interferometry Observation of Rocket-Triggered Lightning, T. IEE Japan, 117-B, 494-499, 1997.

Williams, D. P., and M. brook, Magnetic measurements of thunderstorm currents, J. Geophys. Res., 68, 3243-3247, 1963.

(Received November 28, 1998; revised January 9, 1999: accepted January 27, 1999) 